\title{
BUILT TO SUIT: DOS ASPECTOS CONTRATUAIS AO DIREITO DE SUPERFÍCIE
}

\author{
Alessandro Hirata* \\ João Manoel Meneguesso Tartaglia*
}

\begin{abstract}
Resumo: O presente trabalho tem como referência principal a análise de toda operação que está direta ou indiretamente atrelada aos contratos built to suit. Nesse passo, serão analisados todos os principais pontos, um a um, desde a inserção da modalidade contratual no ordenamento jurídico nacional até a apuração das interpretações equivocadas quanto a aplicabilidade da Lei do Inquilinato. Um pouco mais além, após detalhada toda operação contratual, direcionaremos o foco da discussão para o direito de superfície, quais desdobramentos e importância nos contratos built to suit.
\end{abstract}

Palavras-chave: Built to suit. Contrato. Lei de Locações. Direito de Superfície. Inquilinato.

\section{BUILT TO SUIT: CONTRACT LAW ASPECTS OF SURFACE}

Abstract: The main reference of this work is the analysis of any operation that is directly or indirectly tied to contracts built to suit. In this study, all the key points will be analyzed one by one from the insertion of the contractual modality in the national legal order until the calculation of the misinterpretations regarding the applicability of the Tenancy Law. Furthermore, we will direct the focus of the discussion to the surface right and its unfolding and importance in the contracts built to suit.

Keywords: Built to suit. Contract. Leasing Law. Surface Law. Tenancy.

\footnotetext{
*Doutor em direito pela Ludwig-Maximilians-Universität München. Livre-docente em Direito Romano pela Universidade de São Paulo. Professor Associado da Faculdade de Direito de Ribeirão Preto da Universidade de São Paulo - USP. E-mail: alessandro.hirata@usp.br.

*Advogado. Pós-graduado em Direito Civil pela Faculdade de Direito de Ribeirão Preto da Universidade de São Paulo - USP. E-mail: joaomeneguesso@yahoo.com.br.
} 


\section{INTRODUÇÃO}

Muitas vezes, posto a vagarosidade do Poder Legislativo, o Poder Judiciário é provocado à solucionar e mediar conflitos onde a solução encontrada foge totalmente da literatura pátria. A resposta dada pelo Judiciário, muitas vezes escorada em princípios constitucionais, acaba por "legislar" e abrir, quando não, insegurança jurídica. Tais hipóteses, não fogem do tema proposto, qual seja o contrato built to suit.

Sabe-se que nosso ordenamento jurídico ampara a autonomia da vontade. A sociedade é livre para contratar, exceção feita aos casos previstos em lei. Há leis que demonstram os passos a serem percorridos pelas partes para consolidarem sua vontade, já em outros casos, a lei nada fala.

Nos contratos built to suit, não será diferente. Por força e modo de sua inserção no ordenamento jurídico, o operador do direito, diante do caso concreto, encontra certa dificuldade em qual legislação aplicar. Se preserva um interesse e aplica referida lei, ou se reduz o valor da multa contratual e aplica outra lei. Diante das vicissitudes que se podem encontrar, no que tange especificamente aos contratos built to suit, é que se tentará solucionar, esclarecer e contribuir com o presente trabalho.

Desse modo, o objetivo principal desse trabalho é analisar todos os elementos do contrato built to suit, a fim de poder caracterizá-lo e classificá-lo, diante de uma doutrina ainda incipiente sobre o tema. Além de fortalecer e tornar claro pontos conflitantes acerca da modalidade contratual adotada para estudo, dar-se-á enfoque para o direito real de superfície, objetivo secundário do trabalho. Na maioria dos casos nos preocupamos com outros aspectos contratuais, principalmente financeiros, e nos esquecemos de outros direitos inerentes ao negócio jurídico.

Como metodologia, far-se-á análise da doutrina pertinente ao tema, que ainda se encontra em fase inicial de desenvolvimento. Do mesmo modo, o estudo jurisprudencial também é limitado, em virtude dos poucos casos decididos, que também serão aqui tratados. Ainda, utilizar-se-á o método de direito comparado, uma vez que o contrato built to suit tem origem nos Estados Unidos e encontra maior evolução em outros países.

O trabalho tem como desenvolvimento em sua fase inicial as características fundamentais do contrato built to suit, tratando de sua origem e seus elementos principais e mais frequentes. Em seguida, far-se-á estudo da operação imobiliária-financeira do contrato built to suit, de suma importância para traçar o contexto mercadológico que dá suporte ao 
contrato atualmente. Ainda, será analisado o direito de superfície, com seus aspectos gerais no direito brasileiro e aplicados ao contrato built to suit. Por fim, serão apontadas algumas conclusões para uma melhor disciplina do contrato built to suit no Brasil.

A pertinência do tema escolhido, mostra-se totalmente viável diante da crescente necessidade pela busca do operador do direito em soluções palpáveis. A escassa jurisprudência (e também doutrina sobre o tema), somada à alteração do artigo $4^{\circ}$ e inclusão do artigo 54-A à Lei do Inquilinato, ocasionada pelo advento da Lei n. 12.744 de 2012, criou-se um cenário totalmente embaraçoso.

\section{CONTRATO BUILT TO SUIT}

\subsection{Origem}

Em virtude dos avanços econômicos e diante da necessidade em sistematizar as relações imobiliárias, surgiu, durante a década de 50, nova modalidade contratual denominada built to suit. Sua origem foi fortemente difundida nos Estados Unidos, tendo, posteriormente, ramificações e vasta influência em outros continentes, tais como o Europeu e o Asiático.

No Brasil, referida modalidade contratual teve sua primeira aparição em meados dos anos de 1994 e 1995, com o Sr. Gilberto Buffara, para construção de uma indústria para a Gillete, no Rio de Janeiro.(CILLI, 2004, p. 135). No Estado de São Paulo, a negociação envolvendo o modelo contratual built to suit, destinou-se à construção de uma instituição educacional, no caso, a sede do Ibmec-SP, no ano de 2005. Nota-se, mesmo entre Estados vizinhos, um lapso temporal para o surgimento do modelo contratual em estudo. Iniciou-se no Estado do Rio de Janeiro e, somente após 10 (dez) anos, o Estado de São Paulo teve seu primeiro caso.

A cultura do built to suit está em constante expansão. A necessidade para redução de gastos, aliada com a importância da captação de recursos, faz com que investidores optem pela construção sob medida.

\subsection{Conceito}

Longe de uma terminologia que indique com precisão o âmago, a essência do contrato ora debatido, a míngua doutrina possui certa divergência. Deve-se agir com cautela ao atribuir determinada nomenclatura ao built to suit, pois, além de distorcer o real significado de toda 
operação contratual, pode ocasionar vários prejuízos para solução de questões práticas, inclusive pelo Poder Judiciário.

Muito distante de uma tradução ou nomenclatura correta para built to suit, encontramos na literatura vários significados que se aproximam de uma definição perfeita.

Há doutrina que o define como "construído para servir", "construção sob encomenda" ou como sendo "construção vinculada a uma locação ou arrendamento pré-contratados". (BENEMOND, 2015, p. 16). Outras doutrinas procuram sistematizar tais contratos pela tradução literal como "construir para servir". (ZANETTI, 2011, p. 103). A recente Lei n. 12.744 de 2012, que alterou o artigo $4^{\circ}$ e acrescentou o artigo 54-A à Lei do Inquilinato (Lei n. 8.245 de 1991), traz como nomenclatura "contratos de construção ajustada".

As diferenças estão presentes também na grafia e qual tempo está ou será empregada a palavra. No Brasil, adotou-se a nomenclatura built - no passado -, que deriva verbalmente de to build - no presente. Há quem prefira utilizar built to suit, há quem prefira build to suit. Importa salientar, que em tradução literal, build significa construir/edificar, o que já se torna mais claro conceituar os contratos sob encomenda.

Por built to suit entendemos seu conceito como sendo um negócio jurídico, onde uma empresa ou investidor - não necessariamente uma pessoa jurídica -, contrata uma ou mais empresas - necessariamente pessoa(s) jurídica(s) -, para levantarem, averiguarem e viabilizarem a construção ou reforma de um estabelecimento essencialmente comercial ou industrial, sendo que a empresa contratada deverá se ater a todas especificações fornecidas pelo contratante, tais como a localização, cores, tamanhos, logística, público alvo, espaços e etc. A parte contratante não arcará, até o fim da construção ou reforma, com os gastos despendidos, indicando apenas os requisitos para a construção. Ao fim da construção pela empresa contratada, o estabelecimento estará disponível ao contratante e, este, por sua vez, remunerará as partes envolvidas pela desenvolvimento da obra. A remuneração a ser paga pela parte contratante, corresponde a soma de diversos itens: $i$ - gastos com materiais para construção; ii- gastos com mão de obra específica; iii- gastos em virtude da "locação" do terreno e "imóvel" construído ou reformado.

Em síntese, afirma-se que por força do contrato built to suit, dada pessoa se obriga a levar a efeito certa construção, conforme determinadas especificações e, em seguida, conferir o direito de uso e fruição ao outro contratante, contra o pagamento de determinado valor. (ZANETTI, 2011, p. 103). 
É certo que diante das pouquíssimas literaturas existentes sobre o tema, encontraremos em cada uma delas um conceito diferente para o buil to suit. Doutrinas que versam exclusivamente a área da construção civil, tendem a possuir um conceito voltado para sua atuação. Já uma doutrina direcionada para o ramo de investimentos, possuirá um conceito voltado à economia. Porém, na seara jurídica, compete à doutrina e à jurisprudência, estipularem conceitos que harmonizam todas as áreas e especialidades suscetíveis de atuação nas operações contratuais sob encomenda.

Pensamos que de nada adiantará uma lei regulamentar determinada operação, se a interdisciplinaridade das matérias que a compõe não caminharem juntas. A complexidade do tema demanda maiores aprofundamentos, inclusive e de maneira inaugural, sobre as expressões utilizadas. Há divergência doutrinária. Ora se fala em aluguel, ora se fala em contraprestação, ora se fala em remuneração.

\subsection{Partes do contrato built to suit}

Ponto de muita divergência consiste em delimitar as partes do contrato. Pelo fato da Lei n. 12.744 de 2012, ter modificado o artigo $4^{\circ}$ e inserido na Lei de Locações o artigo 54-A, leva-se - em um primeiro momento - à falsa impressão de que as partes principais seriam locador(es) e locatário(s).

Como já esclarecemos anteriormente, a inserção desta nova modalidade contratual no ordenamento jurídico ocorreu em virtude dos anseios econômicos que batiam à porta do cenário mercantil brasileiro. A ânsia do setor econômico pela regulamentação levou o legislador a desafogar o artigo 54-A na Lei de Locações.

Não acreditamos, então, que as partes principais do contrato built to suit sejam ou tenham a mesma denominação das partes que celebram um contrato típico de locação de imóvel para fins residenciais. Não concordamos pelo simples fato da construção sob encomenda não ser caracterizada com uma locação. A operação contratual em debate é de uma macroescala, algo que transcende qualquer contrato onde as partes procuram instalar um escritório empresarial.

Na falta de uma terminologia adequada, filiamo-nos que seriam partes do buil to suit: a) o empreendedor ou investidor, sendo aquele que irá financiar, captar e arcar com os custos e gastos para construção sob encomenda, ou reforma substancial; e b) explorador ou usuário, sendo aquele que irá ocupar o imóvel após a reforma ou construção, com finalidade 
exclusivamente econômica/mercantil. Atribuímos à uma das partes a palavra "explorador", não no sentido pejorativo, que causa malefícios, mas sim no sentido daquela parte que irá explorar uma ou várias atividades econômicas após construído ou reformado o imóvel pelo empreendedor.

\subsection{Cláusula penal}

É pertinente pensarmos que muito embora os contratos sob encomenda possuam um baixo nível de risco de inadimplemento entre as partes, especialmente para o usuário, sendo o responsável pelo pagamento ao investidor, o atraso e a falta de pagamento poderão ocorrer. Caso não seja pelo inadimplemento, outros fatores podem culminar na rescisão contratual.

As obrigações nascem para serem cumpridas. O contrato built to suit, em especial pela vultuosidade, merece atenção redobrada para que seja satisfeito durante toda sua vigência. Pensando nisso e a fim de evitar a rescisão por qualquer motivo, podendo uma das partes denunciar o contrato antecipadamente, estipula-se uma multa ou cláusula penal.

Se filiássemos à corrente de que o contrato built to suit é regulamentado pela Lei de Locações, admitiríamos que o investidor ou empreendedor jamais poderia resilir de forma unilateral o contrato por prazo determinado. Porém, no cenário em que se encontra inserido a construção ajustada, entendemos ser possível a recisão contratual unilateral pelo usuário e/ou pelo investidor.

O Código Civil traz, em seu artigo 473, a possibilidade de resilição unilateral dos contratos. Porém, em seu parágrafo único, faz ressalva quanto à natureza do contrato e se uma das parte fez investimentos consideráveis para a execução do contrato. É no mesmo sentido que o artigo 54-A, da Lei do Inquilinato, que aponta no caso de denúncia antecipada do vínculo locatício pelo locatário, este compromete-se a cumprir a multa convencionada, que não excederá, porém, a soma dos valores dos aluguéis a receber até o termo final da locação.

Mesmo com as disposições contidas no Código Civil e na Lei de Locações, pensamos que é possível o empreendedor resilir unilateralmente o contrato e, sendo de iniciativa deste, deverá arcar com a multa contratual prevista, inclusive com os lucros cessantes que o explorador da atividade econômica iria auferir caso continuasse até o término contratual com sua atividade econômica. Os valores a título de lucros, constituiria uma média dos meses em que o usuário exerceu sua atividade econômica, a fim de evitar enriquecimento sem causa. 


\section{BUILT TO SUIT: DOS ASPECTOS CONTRATUAIS AO DIREITO DE SUPERFÍCIE}

Caso a iniciativa da resilição seja do usuário, este deverá arcar com multa prevista no contrato. Esta multa, porém, não deve ser composta pelo meses restantes para o término do contrato, mas sim que cubra todos os gastos efetuados pelo investidor em prol da construção ou reforma, acrescida de 50 \% (cinquenta por cento) dos lucros restantes caso o contrato chegasse naturalmente ao fim.

Assim, temos que a remuneração mensal paga pelo usuário ao investidor é composta por duas partes: $1^{\text {a }}$ que visa remunerar o empreendedor pelos gastos na construção ou reforma; a $2^{a}$ parte que visa remunerar o empreendedor pelos lucros de um "locação". A soma dessas duas partes é a remuneração paga mensalmente pelo usuário ao investidor.

Portanto, na hipótese dos gastos efetuados pelo empreendedor com a construção ou reforma, no decorrer do contrato, já tenham sido supridos pela remuneração paga mensalmente pelo usuário, sobrevindo a resilição por parte do usuário, caberá ao investidor apenas metade dos lucros que receberia nos meses subsequentes, compreendido entre a resilição até o término do contrato. Caso não tenha suprido os gastos com a obra, fará jus ao recebimento pelo investimentos, acrescido da metade dos lucros que receberia até o término do contrato.

\subsection{Prazo(s) e Renovação(ões)}

Diferentemente da disciplina aplicada aos prazos pela Lei do Inquilinato nos contratos de locação para fins residenciais ou para os contratos de locação para fins comerciais, temos que para os contratos sob encomenda tal regra não se faz presente. Como defendemos até o presente momento, a Lei de Locações não deveria regulamentar os contratos sob construção ajustada. O artigo 54-A foi uma válvula de escape para o Legislador. Não podemos confundir os institutos, mas também não podemos ignorar que há semelhanças entre locação e built to suit.

Comungamos, via de regra, pela não aplicação da Lei n. 8.245 de 1991 aos contratos sob construção ajustada, em especial à matéria de prazo/vigência contratual e a possibilidade de renovação. Nos contratos de locação, tanto residência quanto comercial, não há construção ou reforma substancial por parte do locador. Admitimos que o locador possa até construir um imóvel e destiná-lo à locação, porém, não cobrará do locatário o preço despedido pela construção, apenas transferirá ao inquilino o lucro (aluguel), bem com os encargos com água, energia elétrica e alguns impostos. O mesmo se aplica aos imóveis com fins comerciais. Geralmente os prazos para tais locações compreendem de 01 (um) até 03 (três) anos, podendo 
ser prorrogado sucessivamente, ou, na falta de prorrogação, passados 30 (trinta) dias sem oposição do locador, considera-se o contrato prorrogado, nas mesmas condições anteriormente contratadas, por prazo indeterminado.

De outro modo, o figura do built to suit - ressalvadas as semelhanças - apresenta características distintas da locação comum, inclusive quanto aos prazos. O contrato sob ajuste é fruto de uma vontade específica do usuário em ter seu imóvel construído ou reformado significativamente sobre requisitos em condições especiais. Assim, contrata com um empreendedor a execução ou reforma de tal obra. Os gastos ficam por conta do investidor, que almeja, após a entrega do imóvel, ser ressarcido mensalmente pelo usuário.

A obra objeto do built to suit tem investimentos vultosos, que não ressarciria o investidor se comparado com os preços - muitas vezes misóginos - do aluguéis pagos pela locação tradicional. A remuneração paga mensalmente ao empreendedor visa ressarci-lo pelos gastos despedidos com a obra, bem como fornecê-lo uma margem de lucro. Assim, para que o investidor recupere seus gastos e tenha um determinado de lucro, os prazos para os contratos sob construção ajustada são eminentemente superiores, compreendidos no mínimo de 10 (dez) anos até 15 (quinze) ou 20 (vinte) anos.

Acreditamos que o contrato buil to suit não poderá ser renovado. Entendemos que tal modalidade de contração não permite - como regra geral - renovação, pois seguindo a linha de raciocínio adotada até o presente momento, se o prazo contratual longínquo visa remunerar o investimento feito, bem como auferir lucro ao investidor, findo o prazo contratual e mantida a remuneração paga pelo usuário, o empreendedor estará diante de um duplo ressarcimento pela construção ou reforma significativa.

Ainda, só haverá renovação contratual nos moldes e com a finalidade do instituto built to suit, quando, ao término do primeiro prazo contratual, as partes em comum acordo consentirem e o investidor realizar reforma significativa no imóvel. Caso não haja a reforma, as partes estarão diante uma locação para fins comerciais, devendo ser reduzida drasticamente a remuneração mensal paga ao investidor, estando as partes submetidas a aplicação da Lei de Locações.

\section{A ESTRUTURA DA OPERAÇÃO IMOBILIÁRIA-FINANCEIRA DO CONTRATO BUILT TO SUIT}




\section{BUILT TO SUIT: DOS ASPECTOS CONTRATUAIS AO DIREITO DE SUPERFÍCIE}

\subsection{O mercado imobiliário-financeiro}

O mercado de imobiliário, durante décadas, oscilou constantemente. Por ser atrativo aos olhos dos investidores, muitas vezes respectivo ramo operava em constante ascensão. Por outro lado, em virtude da falta de uma regulamentação legislativa e diante das indecisões do Poder Judiciário, amargava grande baixa econômica.

Não há como negarmos que o ramo imobiliário, especialmente no que tange à locação de casas e estabelecimentos comerciais, tornou-se um grande negócio para àqueles que poderiam dispor de um vasto capital voltado ao investimento. Atualmente, este mesmo mercado que operava em alta, está experimentando um déficit considerável, além da grande oferta e da baixa procura, inquilinos estão tornando-se inadimplentes, gerando prejuízos ao locadores e abarrotando ainda mais a Justiça.

Outro ponto que causou enfraquecimento no mercado imobiliário, gira em torno dos variados compromissos de compra e venda firmados com empresários detentores de grandes porções de terra que, após constituída uma Sociedade de Propósito Específico - SPE, angariavam lucros com a venda parcelada por determinado lote. Quando não se firmavam compromissos, firmavam-se contratos com grandes construtoras visando a compra de um imóvel na planta.

A instabilidade do mercado imobiliário, com o consequente abalo na economia, fez com que no ano de 1964, fosse editada a Lei n. 4.380/64, que inovou ao criar o Sistema Financeiro de Habitação - SFH. É nesse cenário do marcado imobiliário onde a instabilidade financeira encontra-se totalmente presente, distanciando cada vez mais investidores que o contrato built to suit, por sua vez, traz um novo paradigma, proporcionado segurança econômica e, especialmente, jurídica para todas as partes, inclusive aos investidores.

\subsection{Securitização da operação}

A estrutura e o intuito dos contratos sob encomenda é sedimentada com o pensamento voltado exclusivamente na economia. Quando o investidor e o usuário celebram tal contrato, ambos visam angariar lucros. Só que os lucros não ficam adstritos - no caso do investidor - aos pagamentos mensais feitos pelo usuário.

Se fosse assim, de forma estagnada, o retorno financeiro ao investidor seria muito demorado e fugiria completamente da realidade que buscam as partes contratantes. Deste modo, e estando o built to suit atrelado, também, à captação de recursos, com amparo na Lei n. 9.514 
de 1994, que criou o Sistema Financiamento Imobiliário - SFI, o empreendedor poderá comercializar no marcado títulos imobiliários emitidos por uma agência securitizadora.

A Lei 9.541/94, instituiu o Sistema de Financiamento Imobiliário, visando à criação de novas fontes de recursos para os financiamentos imobiliários, com o estabelecimento de condições para desenvolvimento de um mercado secundário. Referida lei criou, entre outros aspectos, novas garantias imobiliárias, definiu a securitização de créditos e possibilitou a emissão de um novo titulo de crédito, o CRI, ${ }^{1}$ caracterizado como o principal título de securitização imobiliária.

Em seu artigo $8^{\circ}$, referida Lei conceitua a securitização de créditos imobiliários como sendo a operação pela qual tais créditos são expressamente vinculados à emissão de uma série de títulos de crédito, mediante Termo de Securitização de Créditos, lavrado por uma companhia securitizadora, sendo que para emissão de tais títulos é necessário constar os seguintes elementos: I - a identificação do devedor e o valor nominal de cada crédito que lastreie a emissão, com a individuação do imóvel a que esteja vinculado e a indicação do Cartório de Registro de Imóveis em que esteja registrado e respectiva matrícula, bem como a indicação do ato pelo qual o crédito foi cedido; II - a identificação dos títulos emitidos; III - a constituição de outras garantias de resgate dos títulos da série emitida, se for o caso.

De forma mais didática, a fim de elucidar melhor o quesito securitização, temos o seguinte gráfico:

\footnotetext{
${ }^{1}$ O CRI consiste em "título de crédito nominativo, de livre negociação, lastreado em créditos imobiliários e constitui promessa de pagamento em dinheiro". Para que um crédito seja considerado como crédito imobiliário é necessário que decorra, de forma direta ou indireta, de um imóvel. São exemplos de créditos imobiliários aqueles advindos de venda, compromisso de venda e compra, locação, financiamento para aquisição, direito real de superfície, entre outros, sendo todos relacionados a imóveis. Vale salientar que é pacífico o reconhecimento de que os créditos advindos de contratos de locação são créditos imobiliários. (FRANCIOZI, 2013, p. 35).
} 

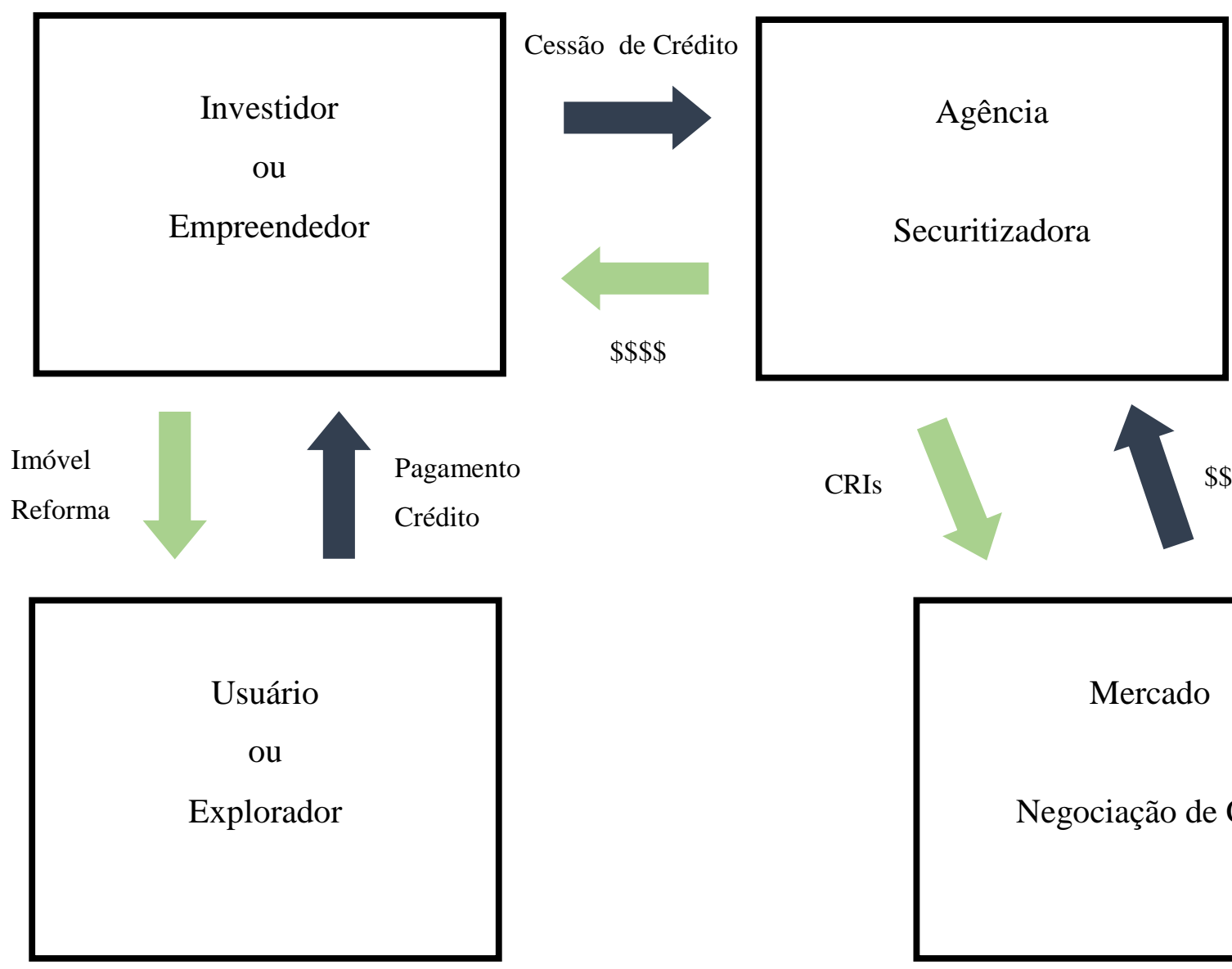

$\$ \$ \$$

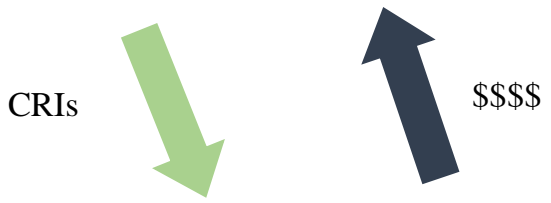

Mercado

Negociação de CRI

Portanto, temos que com a securitização um caminho/forma para captação de recursos pelo investidor, sem que este tenha desembolsar quantias vultuosas para construção sob medida. Em outras palavras, o investidor figura - quando há o envolvimento de securitização - como um intermediário na relação processual. Sendo certo, por vez, que os compradores de CRIs são os reais financiadores da operação contratual sob ajuste.

\section{O DIREITO DE SUPERFÍCIE NO CONTRATO BUILT TO SUIT}

\subsection{Paradigmas históricos e evolutivos do direito de superfície}


O direito de superfície apresenta suas raízes históricas que remontam ao direito romano (MOREIRA ALVES, 2008, p. 358). Sabe-se, porém, que há respeitáveis doutrinas que destoam de uma base exata para o surgimento do direito de superfície. Tais posicionamentos contrários caminham no sentido de que não há material comprobatório suficiente para afirmar que o surgimento de referido instituto deu-se com o povo romano.

Para os romanos, a propriedade representava e se apresentava como um poder absoluto e indivisível. Era concebida como um único poder, onde somente aquele detentor/proprietário poderia dispor de referido bem, possuía caráter perpétuo, onde só por meio da disposição de um ato de vontade é que poderia perder referido bem.

O exercício do poder era tamanho, que o proprietário poderia destruir a coisa/bem sem que sofresse qualquer penalidade. Tal faculdade consistia na maior soberania perante a propriedade. Já que o proprietário poderá usar, fruir e adquirir frutos, poderia, também, fazer o que quisesse, sem qualquer retaliação, pouco importando se os atos praticados pelo proprietário iriam ferir ou ocasionar problemas, por exemplo, ao meio ambiente (MOREIRA ALVES, 2008, p. 297).

Em virtude das características absolutas, individualistas e personalíssimas, entendiase - com base no princípio superficies solo cedit -. que qualquer coisa que brotasse, surgisse ou estivesse sobre o solo da propriedade, por vias do direito natural, incorporava-se ao patrimônio do proprietário (MOREIRA ALVES, 2008, p. 310). Sendo que, naquele período, não havia a concepção da separação entre o solo e a construção. Em outras palavras, não havia para a propriedade do ius civile uma separação de uma edificação com a superfície.

Em contrapartida, mesmo diante da característica absoluta instituída à propriedade, era possível encontrar várias flexibilizações ou restrições. Haviam delimitações quanto ao direito de vizinhança, bem como em caso de construção, que o proprietário deixasse um espaço ao redor para viabilizar a circulação.

Diante de algumas flexibilizações ou restrições impostas ao direito de propriedade, com o transcorrer do tempo, o título individualista consagrado pelos romanos vai enfraquecendo, sofrendo alterações, até ceder lugar aos anseios sociais. A propriedade absoluta e individual, com o passar do tempo, tornou-se flexível e deu lugar aos elementos da sociedade.

Diante do cenário instaurado e que estava se sedimentando em Roma, onde ao final do século I houve grande crescimento e aprimoramento nas técnicas de construção, com a consequente criação de estradas e edifícios, o que gerou aglomeração e aumento populacional 
nos grandes centros. O avanço econômico fez com que o direito de superfície começasse a ganhar contornos que visassem, num primeiro momento, a correção de medidas contrárias à geração de lucros. A propriedade, então, começava a perder sua função absoluta e individual, dando margem ao desenvolvimento social e econômico (SILVEIRA MARCHI, 2002).

É de se ressaltar que o direito de superfície instaurou-se, em princípio, no direito público. A justificativa estava atrelada ao fato de que a maior parte das propriedades estavam sob o domínio público, contando com poucas propriedades particulares. Assim, o Poder Público tratou de destinar certa ocupação e reverter os frutos que angariavam para Roma.

O Poder Público, então, arrendava por um grande lapso de tempo para pessoas que tinham interesse em utilizar determinada propriedade, desde que efetuasse o pagamento de um determinado valor. Assim, a pessoa utilizaria a propriedade, poderia edificar, plantar, mediante uma contraprestação convertida ao Poder Público.

Com os avanços ocorridos na sociedade e necessitando de uma maior proteção legal, o direito de superfície deixou de ser um direito estritamente pessoal, passando a compor o núcleo de direitos reais. Tal ascensão acabou por colocar fim ao princípio superficies solo cedit.

Já no Brasil, o instituto do direito de superfície passou por vários aprimoramentos, foi moldado com o tempo e o avanço social. É certo que em solo brasileiro, o direito de superfície foi pouco influenciado pelas leis de Portugal. Sabe-se que em quase nada as ordenações Afonsinas, Manuelinas e Filipinas, contribuíram para o desenvolvimento do instituto no Brasil.

Mesmo com toda influência que Portugal exercia em solo brasileiro, somente com a Lei de 9 de julho de 1773, contemplou-se o direito de superfície. Referida lei contribuiu diretamente para que fosse evitado o abuso e atrocidades por parte dos proprietários das terras em relação aos que dela utilizavam/exploravam. Em outras palavras, o diploma de 9 de julho de 1773 tratou de barrar a alta cobrança e a imposição de exorbitantes valores pelos proprietários em face dos que utilizavam a terra como superficiários.

\subsection{O direito de superfície no Código Civil de 1916 e no Código de 2002}

O direito de superfície no Brasil tornou-se importante com o passar do tempo. A ideia de propriedade era estagnada, não despertando maiores interesses do legislador. O Código Civil de 1916 não trouxe qualquer delimitação acerca do tema. Quando da inserção do instituto pela revisão do Projeto do Código, foi suprimido ao tramitar no Congresso Nacional pela Câmara 
dos Deputados, que pouco importou com sua codificação, sob o argumento que tal instituto estava em total desuso.

A tendência assumida pelo Código de 1916 em não incluir o instituto, parecia influenciar fortemente o anteprojeto do Código Civil de 2002, eis que não havia qualquer previsão para inclusão do direito de superfície no rol de novidades dos direitos reais.

Porém, com o advento da Constituição Federal de 1988, trazendo em seu bojo artigos e princípios que atribuíam e direcionavam - inclusive o legislador - para a importância da função social, entrou em vigor o Estatuto da Cidade, muito antes do que viria a ser o novo Código Civil, em 2002. A Lei n. 10.257 de 2001, foi criada para regulamentar os artigos 182 e 183 da Constituição de 1988. Inovou ao trazer o direito de superfície, precisamente inserido no artigo $4^{\circ}$, inciso V, alínea l. Além da inovação, o Estatuto reservou dos artigos 21 até o 24 para tratar especificamente sobre o tema. Em seguida, o Código Civil confirma e admite o Estatuto da Cidade, e contempla nos artigos 1.369 até 1.377, o direito de superfície.

Acreditamos que a maior influência para inserção do direito de superfície no Código Civil, foi exercida através das modificações ocorridas pela Constituição Federal de 1988 e, em seguida, pela criação do Estatuto da Cidade. Mesmo com a criação do Estatuto e posterior regulamentação do Código Civil, o direito de superfície encontra-se distante de uma pacificação na legislação.

\subsection{O direito de superfície nos contratos built to suit}

Diante de tudo que procuramos abordar, reforçamos que o direito de superfície visa separar a propriedade do solo com a utilização do solo. O proprietário cederá ao superficiário o direito de usar referido espaço de terra, constituindo-se uma exceção, pois o que for plantado ou edificado não pertencerá ao proprietário.

Pelo novo instituto, uma pessoa cujo terreno não seja apropriado para construção que pretende erigir pode, por exemplo, permutar o uso do solo, temporariamente, mantendo a propriedade deste, com outra pessoa que possua terreno que atenda às suas necessidades, cedendo, por outro lado, a esta, que nele tem interesse, o direito de superfície de seu imóvel. Assim, o proprietário de um terreno localizado na zona central, próprio para a edificação de um prédio de escritórios, mas que deseja investir na construção e montagem de uma indústria, pode permutar o uso do solo deste seu imóvel com o de um terreno localizado na perificaria da cidade 


\section{BUILT TO SUIT: DOS ASPECTOS CONTRATUAIS AO DIREITO DE SUPERFÍCIE}

cujo proprietário tem interesse em construir um prédio de escritórios. (GONÇALVES, 2013, p. 449).

Por outro lado, indaga-se se haveria a possibilidade na concessão do direito de superfície quando existir plantação ou construção anterior ao início do direito pelo superficiário. Se seguirmos a corrente de que é plenamente possível, estaríamos sujeitos a inviabilidade do built to suit, excetuando-se quando destinar à reforma substancial. Caso não seguirmos pelo caminho da impossibilidade na concessão do direito de superfície, estaríamos viabilizando o instituto da construção sob encomenda, quando não abarcado pela reforma expressiva.

Caso se entenda que o direito de superfície não incide sobre construções já existentes na data de sua concessão, podemos afirmar que não seria possível acordar em um contrato built to suit, que o empreendedor ficaria obrigado a obter o direito de superfície de um terreno com construção para que fosse realizada reforma substancial de tal construção. (BENEMOND, 2015, p. 62).

Ao nosso sentir, pensamos que independentemente da existência de imóvel ou plantação no ato da concessão do direito de superfície, há plenas possibilidades na constituição do built to suit, pois diante do que ficar acordado para utilização do solo, a construção que em tese inviabilizaria o contrato para construção sob encomenda, poderá ser derrubada. A ideia central é construir sob ajuste, nos moldes do contratante, mesmo que para isso seja preciso derrubar o imóvel construído e concedido pelo direito de superfície, desde que fique acordado a demolição.

O mesmo entendimento aplicamos aos tributos que deverão incidir e de quem seria a capacidade para pagá-los. Tanto o Estatuto da Cidade, quanto o Código Civil, possuem previsão e atribuem o pagamento dos encargos e tributos ao superficiário, ou seja, aquele que recebe a concessão. Todavia, o Estatuto flexibiliza tal regra e aponta que caso seja acordado de forma diferente, o superficiário poderá pagar tais despesas proporcionalmente à sua utilização do direito de superfície ou, até mesmo, que fique isento do pagamento.

Para o built to suit, a possibilidade de ajuste quanto ao pagamento de encargos e tributos é relevante, eis que favorece tanto o investidor, quanto usuário.

Por fim, cumpre salientar que o direito de superfície concedido não pode ter prazo inferior que o da vigência do contrato sob construção ou reforma ajustada. Isso pelo simples fato do proprietário do solo reivindicar a posse direita estando o built to suit em plena vigência e o direito de superfície extinto. Certamente causaria grande confusão. 
A formas de extinção do direito de superfície, conforme previsto no artigo 23 do Estatuto da Cidade, ocorrerão com: I - advento do termo ou II - descumprimento das obrigações contratuais assumidas pelo superficiário. Já doutrina trata outras formas de extinção do direito de superfície, porém, pensamos que independente da forma de resolução, pensamos que o mais viável quando envolver contratos sob ajuste, é focarmos na mitigação dos riscos que as partes poderão sofrer.

Note-se, que a contratante de um empreendimento built to suit construído (ou reformado) em terreno objeto de direito de superfície deve observar as hipóteses de extinção da superfície, uma vez que a execução do built to suit dependerá da vigência do contrato de superfície. Desta forma, recomenda-se que o proprietário fundeiro concorde com o desenvolvimento de um empreendimento em caráter built to suit no terreno. Além disso, como já exposto acima, é preciso que o prazo da concessão do direito de superfície seja superior ao prazo do contrato built to suit e, conforme o caso, que se estabeleça penalidade ao empreendedor/superficiário em caso de extinção da superfície, seja por sua denúncia ao contrato, ou seja por sua culpa ou dolo. Como alternativa à situação, podem as partes acordar no contrato built to suit que, em caso de extinção do direito de superfície, o proprietário fundeiro dará continuidade ao built to suit celebrado com a contratante, na posição de empreendedor. Em tal hipótese, deverá o proprietário fundeiro assinar o contrato built to suit - uma vez que assumirá obrigações - e acordar um mecanismo financeiro com o empreendedor original do built to suit (superficiário), de forma a tonar a avença vantajosa para o proprietário fundeiro. (BENEMOND, 2015, p. 69).

Acreditamos, desta maneira, que a operação envolvendo o direito de superfície, questões tributárias, até chegarmos a consolidação do buil to suit, necessita ser estudada cautelosamente, mostrando as partes contratantes os bônus e ônus de cada uma, inclusive qual a extensão dos lucros que receberá e qual a dimensão dos prejuízos que poderá sofrer.

O built to suit é pensado e estruturado para fornecer e disponibilizar uma série de benefícios, além dos lucros. As partes contratantes ganham, o mercado avança economicamente, as sociedade possui uma mais uma fonte de emprego. E o direito de superfície, este jamais poderá desaparecer do ordenamento jurídico, ao contrário, deverá ser estudo com maior profundidade para que seja aplicado de forma correta, sem maiores conflitos como tem ocorrido entre Estatuto da Cidade e Código Civil. 

CONCLUSÕES

Procuramos, diante de tudo o que foi exposto, dar novos ares e nova sistemática aos contratos denominados built to suit, ou contratos sob construção ajustada. Os contornos que procuramos desenhar baseiam-se em literaturas que pouco traduzem a real necessidade de enfrentarmos tal tema que encontra-se em vasta ascensão.

O modelo contratual estudado, de origem norte americana, possui outras raízes e outros intuitos. A inserção e, consequente adaptação em solo brasileiro ocasionou, tem ocasionado, e ocasionará grandiosos problemas caso não seja bem concebido. Não podemos e não devemos, neste momento, deixar de esmiuçar o propósito que tal instituto visa atender. Claramente não se trata de locação comum, muito menos de locação comercial.

Além de delimitarmos os contornos que envolvem a construção sob ajuste, pontuando os itens que julgamos essenciais para melhor concepção do instituto. Traçamos, também, detalhes relativos ao direito de superfície, partindo desde seu surgimento até a sua importância nos contratos para reforma ou construção sob medida.

De maneira mais detalhada, concebemos o built to suit como instituto inovador, capaz de transformar a sociedade e angariar renda, gerando incentivos e aquecendo o cenário econômico. Todavia, para que essa operação ocorra, atinja sua finalidade, é preciso cooperação.

A operação para uma reforma substancial ou construção sob moldes específicos, demanda o envolvimento de diversos setores, diversas disciplinas, variadas informações e uma sólida estrutura. Não é simples falarmos em built to suit se ao menos não tivermos propósitos específicos e partes seguras, inclusive disposição financeira para custear vultuosas obras.

Em virtude de toda essa complexidade que envolve o instituto em análise, é que procuramos, por muitas vezes, nos posicionarmos acerca da aplicação ou não da Lei n. Lei n. 8.245 de 1991. Os poucos trabalhos que versam sobre o tema built to suit, não tratam de forma enfatizada a aplicabilidade da Lei de Locações, se o artigo $4^{\circ}$ necessitava de modificação e se o artigo 54-A foi incorretamente inserido no referido diploma locatício.

Assim, além de desmistificarmos pontos conflitantes acerca das disposições envolvendo a construção sob medida, procuramos apontar os principais aspectos envolvendo o direito de superfície. Por outro lado, não sendo objeto central deste trabalho, mas não menos importante para temática, esmiuçamos o caminho obscuro que perambulava acerca da aplicação ou não da Lei do Inquilinato. 
Filiamos à corrente de que não se aplica tal lei ao instituto do built to suit. Não concordamos com a aplicação, em regra, por vários motivos, desde do fato de não ser uma relação de locação, não possuir reajuste nos pagamentos, até concebermos que o modelo contratual em estudo é eminentemente empresarial.

De outro modo, pensamos que em casos específicos, taxativos, desde que previamente estipulado em contrato pelas partes, a Lei de Locações poderá ter incidência. Contudo, ressaltamos que tal aplicação não é de caráter irrestrito, mas sim uma aplicação moderada, cautelosa e que obrigatoriamente seja benéfico para ambas as partes. Caso uma parte seja prejudicada, não se aplica tal lei.

Temos que ressaltar, também, que diante de todo cenário que nos é posto, o built to suit se mostra como meio hábil e propício na capitação de investimentos ao comercializar CRIs no mercado, através uma empresa securitizadora.

Por fim, conclui-se que não há como esgotarmos todo o conteúdo aplicável ao modelo contratual em tela, até mesmo pelo fato dele envolver outros setores e outras disciplinas. Porém, acreditamos que compete à literatura jurídica dar o principal contorno para que os demais setores sociais possam ter um rumo a ser seguido.

Pensamos que compete também à doutrina, traçar pontos claros e precisos acerca da incidência de uma ou outra lei, de como fica as disposições registrais, se há ou não multa, ou se é possível revisarmos ou não os pagamentos.

Caso não haja tal regulamentação, caso haja inércia, o instituto estará fadado ao insucesso, pois ao relegarmos a aplicação para qualquer diploma, e caso os tribunais não constituam uma jurisprudência sólida, estaremos sujeitos ao abandono de futuros investidores em nossa sociedade, o que diminuirá, consequentemente, ainda mais a economia de nosso pais.

Todavia, entendemos com a solução imediata e mais adequada para solução do conflito envolvendo o modelo contratual built to suit, é a retirada da sua previsão da Lei de Locações, com a promulgação de uma lei específica visando regulamentar tal instituto. Durante o período de elaboração e aprovação da referida lei, a sugestão fica por conta do incentivo à palestras, seminários, debates e produção de trabalhos acadêmicos que tragam soluções adequadas e possíveis.

Um outro aspecto possível visando à solução, é a doutrina doutrinar e se posicionar fortemente, delimitando os traços e a finalidade para qual o built to suit é constituído. A doutrina 
deve exercer seu papel de modo incisivo, norteando o aplicador do direito para a melhor solução.

Acreditamos, por fim, que não podemos, também, deixar o papel da codificação apenas aos legisladores. Devemos, como eternos acadêmicos, promovermos debates, palestras, seminários e, inclusive, incentivarmos à produção e a publicação de artigos científicos acerca do tema estudado. Somente com essa união, estaremos atingindo o ápice daquilo que a sociedade mais espera de nós, uma solução justa.

\section{REFERÊNCIAS BIBLIOGRÁFICAS}

ARAUJO, Paula Miralles de. Contratos Built to Suit: qualificação e regime jurídico. 2015. Dissertação (Mestrado)- Faculdade de Direito - Universidade de São Paulo, 2015. Disponível em: <http://www.teses.usp.br/teses/disponiveis/2/2131/tde-09122015-140803/pt-br.php

BENEMOND, Fernanda Henneberg. Contratos Built to Suit. Coimbra: Almedida, 2015.

BRASIL. Lei $n=4.380 / 64$

BRASIL. Lei no 8.245/91.

BRASIL. Lei no 10.406/02.

BRASIL. Lei ${ }^{\circ}$ 12.744/12.

BRASIL. Projeto de Lei - PL n. 6562/2009. Disponível em: http://www.camara.gov.br/proposicoesWeb/fichadetramitacao?idProposição=463134.

BRASIL. Superior Tribunal de Justiça. Recurso Especial n. 1.521.448 - SP. Caixa Econômica Federal, Valter Machado Luz e Verona Participações LTDA. Relator: Ministro Moura Ribeiro. 31 de mar. de 2015.

BRASIL. Tribunal de Justiça do Estado de São Paulo: Recurso de Apelação n. 20100958.2010.8.26.0100. Alameda Park Restaurantes e Serviços Turisticos LTDA e Maria Renata Baptista Borges (espólio). Relator Serfio Alfieri. 15 de junho de 2015.

CANOTILHO, J. J. Gomes; MENDES, Gilmar F.; SARLET, Ingo W.; STRECK, Lenio L. (Coords.). Comentários à Constituição do Brasil. ed. São Paulo: Saraiva/Almedina, 2013.

CAVAZANI, Cecília Reia. "Built-to-suit”: formas de contratação pela administração pública. Disponível em: lares.org.br/Anais2012/images/633-946-1-DR.pdf.

CHALHUB, Melhim Namem. Direitos Reais. 2. ed. São Paulo: Revista dos Tribunais, 2014. 
CILLI, Fábio. Empreendimentos do Tipo Built-To-Suit: Arbitragem do Valor de Locação em Editais de Concorrência. São Paulo, 2004, p. 135. Escola Politécnica da Universidade de São Paulo.

DA SILVA, Américo Luís Martins. Locação e Despejo. Leme/SP: Cronus, 2016.

DE MELO, Marco Aurélio Bezerra. Breves apontamentos sobre a locação built to suit (construído para servir). Disponível em:< http://genjuridico.com.br/2016/05/09/brevesapontamentos-sobre-a-locacao-built-to-suit-construido-para-servir/>.

DINIZ, Maria Helena. Lei de Locações de Imóveis Urbanos Comentada. São Paulo: Saraiva, 2012.

FARIAS, Cristiano Chaves; ROSENVALD, Nelson. Curso de Direito Civil: Reais. ed. São Paulo: Atlas, 2015.

FIGUEIREDO, Flávio Fernando de; GRAVA, J. William. A economia dos empreendimentos built to suit. Disponível em: http://www.mrcl.com.br/xivcobreap/tt39.pdf.

FRANCIOZI, Luís Henrique da Silveira. Operações Built To Suit Antes e Depois da Lei $n^{o}$ 12.744/12 - O Estudo de Caso do Hospital Infantil Sabará. São Paulo, 2013. Escola Politécnica da Universidade de São Paulo.

FORGIONI, Paula A. Teoria geral dos contratos empresariais. São Paulo: Revista dos Tribunais, 2009.

GABRIEL, Luís André Garrido. Estruturas de Funding Para Empreendimentos Buildto-suit no Brasil. Disponível em: www.realestate.br/dash/uploads/sistema/.../pini_colunadefevereiro14_luisandre.pdf.

Escola Politécnica da Universidade de São Paulo.

GAGLIANO, Pablo Stolze; FILHO, Rodolfo Pamplona. Novo Curso de Direito Civil: Contratos em espécie. São Paulo: Saraiva, 2012.

GOMES, Orlando. Contratos. Rio de Janeiro: Forense: 2009.

GOMES, Orlando. Direitos Reais. 21 a ed. Rio de Janeiro: Forense, 2012.

GONÇALVES, Carlos Roberto. Direito Civil Brasileiro: Direito das Coisas. ed. São Paulo: Saraiva, 2013.

JUNQUEIRA DE AZEVEDO, Antônio. Negócio Jurídico: existência, validade e eficácia. 4. ed. São Paulo: Saraiva, 2008.

MAIA, Roberta Mauro Medina. Teoria Geral dos Direitos Reais. ed. São Paulo: Revista dos Tribunais, 2013. 
MARCONDES FILHO, Carlos Fernando Dearo. O Contrato Built to Suit: Uma Análise da Multa. Ribeirão Preto/SP, 2016. - Faculdade de Direito de Ribeirão Preto - Universidade de São Paulo.

MARTINS, Fran. Curso de Direito Comercial. 38 a ed. Rio de Janeiro: Forense, 2015.

MARTINS, Fran. Contratos e Obrigações Comerciais. 17ª ed. Rio de Janeiro: Forense, 2017.

MAZZEI, Rodrigo. Direito de Superfície. ed. Bahia: JusPodivm, 2013.

MOREIRA ALVES, José Carlos. Direito romano. 14ª ed. Rio de Janeiro: Forense, 2008.

PENTEADO, Luciano de Camargo. Direito das coisas. $2^{\text {a }}$ ed. rev. atual. e ampl. São Paulo:

Editora Revista dos Tribunais, 2012.

PONTES DE MIRANDA, Francisco Cavalcanti. Direito das coisas. Direitos reais limitados. Enfiteuse. Servidões; atualizado por Nelson Nery Jr., Luciano de Camargo Penteado. In: Tratado de Direito Privado. Vol. 18. São Paulo: Revista dos Tribunais, 2012.

PONTES DE MIRANDA, Francisco Cavalcanti. Locação de Imóveis e Prorrogação. ed. Campinas/SP: Servanda, 2004.

RIZZARDO, Arnaldo. Contratos. Rio de Janeiro: Forense, 2002.

RODRIGUES, Gabriela Wallau. A Incompatibilidade Sistemática entre o Contrato Built-toSuit e a Lei de Locações. Direito \& Justiça (Porto Alegre. Impresso), v. 41, p. 174, 2015. Disponível em: http://revistaseletronicas.pucrs.br/ojs/index.php/fadir/.

RODRIGUES JUNIOR, Otavio Luiz. Análise comparativista dos contratos built to suit. Disponível em: <http://www.conjur.com.br/2013-abr-10/direito-comparado-analisecomparativista-contratos-built-to-suit.>.

ROPPO, Enzo. O contrato. Coimbra: Almedina, 2009.

SCAVONE JUNIOR, Luiz Antonio; PERES, Tatiana Bonatti (org.). Lei do Inquilinato Comentada artigo por artigo: visão atual na doutrina e jurisprudência. Rio de Janeiro: Forense, 2017.

SILVEIRA MARCHI, Eduardo César Vita, A propriedade horizontal no direito romano. $2^{\mathrm{a}}$ ed. São Paulo: Quartier Latin, 2002.

VENOSA, Silvio Salvo. Lei do inquilinato comentada: doutrina e prática. São Paulo: Atlas, 2015.

ZANETTI, Cristiano de Souza. Built to Suit: Qualificação e Consequências. In: BATISTA, Luiz Olavo; PRADO, Maurício Almeida (org.). Construção Civil e direito. São Paulo. LexMagister, 2011. 